J. Lake Sci.(湖泊科学), 2020, 32(2): 395-405

DOI 10. 18307/2020. 0209

(C) 2020 by Journal of Lake Sciences

\title{
土壤动物对鄱阳湖湿地冬季调落物分解过程的影响”
}

\author{
肖玲, 马燕天,甘志伟, 蔡润发, 李卓琳, 葛 刚 ${ }^{* *}$, 吴 兰 \\ (南昌大学生命科学学院, 鄱阳湖环境与资源利用教育部重点实验室,南昌 330031)
}

\begin{abstract}
摘 要: 为了研究湿地土壤动物对调落物分解速率以及对土壤养分归还的影响, 于 2017 年 11 月份在鄱阳湖湿地收集苔 草 (Carex cinerascens)、南荻 ( Triarrhena lutarioriparia) 和芦苇 (Phragmites australis) 3 种植物的调落物, 利用调落物袋法开展 原位的模拟实验. 研究中使用了网孔大小分别为 $4.5 \mathrm{~mm}$ (大) 和 $0.1 \mathrm{~mm}$ (小) 的分解袋来对比分析土壤动物的影响. 结果 表明: 不同物种之间调落物分解速率有差异, 苔草的分解速率显著大于南荻和芦苇, 南荻与芦苇的分解速率差异不明显; 调落物的分解速率与调落物总有机碳和总氮的积累量 $\left(N A I_{\mathrm{TOC}} / N A I_{\mathrm{TN}}\right)$ 呈负相关, 与残余调落物质量呈负相关, 与调落物 总磷含量呈正相关; 调落物总氮含量在不同物种调落物中差异明显, 表现为苔草 $>$ 芦苇 $>$ 南荻, 并且与分解速率的大小关 系相对应, 因此高氮植物调落物的分解速率较快; 土壤动物能够提高分解速率, 促进调落物营养元素的释放, 进而调节调 落物中 C、N、P 元素向土壤养分库的归还过程. 本研究将为湿地生态系统的营养元素循环研究提供科学数据.
\end{abstract}

关键词: 湿地; 调落物分解; 分解速率; 土壤动物; 养分归还; 鄱阳湖; 蚌湖

\section{Influence of soil fauna on the litter decomposition of Lake Poyang Wetland in winter*}

\author{
XIAO Ling, MA Yantian, GAN Zhiwei, CAI Runfa, LI Zhuolin, GE Gang *** \& WU Lan \\ ( School of Life Sciences, Key Laboratory of Poyang Lake Environment Resource Utilization, Ministry of Education, Nanchang \\ University, Nanchang 330031, P.R.China)
}

\begin{abstract}
To study the effects of soil fauna on the rates of litter decomposition and soil nutrients return, litters of Carex cinerascens, Triarrhena lutarioriparia, and Phragmites australis were collected from Lake Poyang Wetland in November 2017. An in situ simulation experiments with three types of litters were carried out by the litter bag method. Decomposing bags with mesh sizes of 4.5 $\mathrm{mm}$ (large) and $0.1 \mathrm{~mm}$ ( small) were used to assess the contribution of soil fauna in this study. The results showed that: the decomposition rate of litters was different among plants, with a significant higher decomposition rate of $C$. cinerascens than those of $T$. lutarioriparia and $P$. australis. There was a negative correlation between litter decomposition rate and litter carbon accumulation/nitrogen accumulation index $\left(N A I_{\mathrm{TOC}} / N A I_{\mathrm{TN}}\right)$, and the remaining dry mass of litters; while a positive correlation with litter total phosphorus content; the total nitrogen content was different among litters, which has a degressive sequence as $C$. cinerascens, T. lutarioriparia, P. australis; the decomposition rate showed the same sequence among litters-the higher nitrogen litter, higher decomposition rate. The participation of soil fauna promoted the decomposition rate and the release of nutrient elements from litters and then regulated the return process of $\mathrm{C}, \mathrm{N}, \mathrm{P}$ elements to soil nutrient bank. This study will provide scientific data for the study on nutrient cycling of wetland ecosystem.
\end{abstract}

Keywords: Wetlands; litter decomposition; decomposition rate; soil fauna; nutrient return; Lake Poyang; Lake Banghu

虽然湿地面积仅占陆地表面积的 $4 \% \sim 6 \%$, 但其碳储量却占陆地碳储量的 $37 \%{ }^{[1]}$. 湿地生态系统之所 以拥有如此高的碳储量, 主要是因为其特殊的环境条件: 土壤透气性低, 植被覆盖率高. 这些特殊的环境条 件使得有机质分解速率较低, 而植被的生产力较高, 有利于有机质的积累, 因此让湿地成为了陆地生态系统 重要的碳库 ${ }^{[2]}$. 植物调落物是大多数湿地碳的主要来源, 调落物的分解过程对于维持湿地生态系统的稳定

* 2019-07-03 收稿; 2019-08-31 收修改稿.

国家自然科学基金项目 (31560143) 和江西省水利厅科技项目 (KT201505) 联合资助.

** 通信作者;E-mail: gge@ ncu.edu.cn. 
具有重要作用 ${ }^{[3]}$. 调落物分解虽然不是湿地的独属功能, 但湿地很多重要生态功能的实现, 包括气候调节、 碳循环、氮循环和生境可利用性等, 都离不开有机物的分解过程 ${ }^{[3]}$. 调落物分解速率影响湿地有机质的积 累、土壤的理化性质、养分供应和循环以及初级生产力, 正是由于湿地与调落物分解间的这种紧密联系, 使 得调落物分解速率研究成为评估整体生态系统的功能演变的潜在工具 ${ }^{[4]}$. 因此调落物分解速率研究对了解 湿地土壤的养分循环、提高植物生长力、减缓温室效应、保持生态平衡都有重要的意义.

调落物分解过程是由环境 (气温 ${ }^{[5]} 、$ 营养环境 ${ }^{[6]}$ 、地理位置 ${ }^{[7]}$ 等)、调落物质量和分解者共同作用驱动 的, 分解者主要包括土壤动物和土壤微生物 ${ }^{[8]}$. 马瑞研究湿地土壤酶活与调落物分解速率的关系时发现土 壤淀粉酶、蔗糖酶活性与调落物的分解速率呈显著正相关 $(P<0.05)$, 表明微生物是调落物分解的重要参与 者 ${ }^{[9]}$. Chimney 等研究了湿地植物基质对调落物分解速率的影响, 结果表明不同物种之间分解速率有明显差 异 ${ }^{[10]}$. Wu 等研究发现了土壤动物群对调落物分解影响显著, 并随湿地演替和季节变化而变化 ${ }^{[11]}$. 研究中 通过使用不同网孔孔径的调落物袋, 可以排除部分土壤动物对于调落物分解的影响, 有利于评估土壤动物 对于调落物分解的贡献 ${ }^{[12-14]}$. 虽然现在有不少关于土壤动物对调落物分解速率影响的研究, 但是大部分研 究要么集中在单一的分解速率和土壤动物群系组成 ${ }^{[15-16]}$, 要么研究对象为农 田 $^{[14]}$ 、林地 ${ }^{[15-16]}$ 、沙地 ${ }^{[17]}$ 等生 境, 而很少有研究关注大型湖泊湿地土壤动物在对调落物分解速率及其养分归还过程的影响. 而调落物分 解过程不仅仅意味着土壤养分的归还, 还能改良土壤、维持生产力. 有研究表明油杉人工林每年 $\mathrm{C} 、 \mathrm{~N}$ 的归还 量分别高达 $2500 、 68 \mathrm{~kg} / \mathrm{hm}^{2[18]}$, 并且崔鸿侠等在冷杉林中的研究表明调落物能对土壤养分起一定的改良 作用 ${ }^{[19]}$.

鄱阳湖作为中国五大淡水湖中面积最大的湖泊, 其湿地面积达 $3130 \mathrm{~km}^{2[20]}$. 根据崔丽娟报告中的评估 结果显示: 鄱阳湖生态系统服务功能 (调水、固碳、产氧, 保护土壤, 降解污染物) 的价值高达 $3.627 \times 10^{10}$

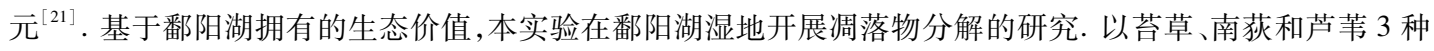
不同的植物调落物为基础, 利用不同网孔的分解袋来比较土壤动物对调落物分解速率的影响, 探究土壤动 物对调落物分解的贡献. 本研究同时探究不同物种调落物之间分解速率的差异和调落物分解对土壤养分归 还的影响, 以便全面了解鄱阳湖湿地的碳循环过程, 以及全球气候变暖背景下湖泊湿地中碳收支平衡的变 化. 本研究的成果将为鄱阳湖以及其它湖泊湿地的科学管理提供科学数据.

\section{1 材料与方法}

\section{1 样地介绍与实验设计}

鄱阳湖位于长江中下游、江西省北部 $\left(28^{\circ} 25^{\prime} \sim 29^{\circ} 45^{\prime} \mathrm{N}, 115^{\circ} 50^{\prime} \sim 116^{\circ} 45^{\prime} \mathrm{E}\right)$, 其水位受赣江、抚河、信 江、饶河、修水五条人湖河流与出湖口长江的双重影响. 鄱阳湖季节性水位波动剧烈, 高水位时水域面积达 $3955 \mathrm{~km}^{2}$, 而低水位时水域面积只有 $146 \mathrm{~km}^{2}$. 剧烈的水位变化形成了广阔的湖滨湿地, 不同的湿地植物沿 着水位高程呈现出带状分布特征. 其中苔草 (Carex cinerascens)、南荻 (Triarrhena lutarioriparia) 和芦苇 (Phragmites australis) 为鄱阳湖湿地分布最为广泛的湿地植被. 鄱阳湖湿地植被的自然调亡发生在冬季枯水 期 (11-1 月), 由于水位下降, 调落物在地表没有积水的情况下开始分解. 之后水位上涨, 调落物在水下分 解 (通常 5-9 月), 然后在退水后继续重复干湿交替的过程直至完全分解, 因此土壤动物对调落物分解的影 响主要体现在冬季枯水阶段. 在这个阶段中一方面土壤动物不受淹水影响活动增加, 另一方面冬季低温也 会限制土壤动物的活动, 因此土壤动物对于调落物分解的影响亟需全面评估. 本研究选取了鄱阳湖湿地中 典型的子湖区湿地一蛙湖湿地进行原位模拟实验. 碟形湖湿地面积巨大, 是构成鄱阳湖湿地的主体, 而蚌湖 湿地是碟形湖湿地的典型代表. 蚌湖湿地地势开阔, 受人为干扰较少, 具有明显带状分布的植被群落, 沿湖 岸到湖心方向依次分布芦苇、南荻和苔草群落. 本研究分别在 3 种植被带下布设 1 条样带, 每种植被样带分 别设 3 个平行样地, 每个样地为直径大约 $5 \mathrm{~m}$ 的圆, 平行样地之间相距约 $100 \mathrm{~m} .3$ 条样带下土壤均为壤质黏 土(砂土: $22 \% \sim 30 \%$; 粉砂土: $41 \% \sim 47 \%$; 黏土: $22 \% \sim 35 \%$ ). 3 种植物调落物 (苔草一南荻一芦苇) 中初始的 木质素含量百分比分别为 $7.2 \% 、 11.9 \% 、 10.3 \%$, 纤维素含量分别为 $31.4 \% 、 36.8 \% 、 25.3 \%$, 半纤维素含量分别 为 $21.0 \% 、 27.7 \% 、 30.0 \%$.

本研究于 2017 年 11 月下旬在鄱阳湖蚌湖湿地采集芦苇、南荻和苔草调落物样品运回实验室, 在清理掉 
表面泥沙后自然阴干, 分别装人两种不同孔径的网袋中. 孔径为 $0.1 \mathrm{~mm}$ 的调落物网袋 (标记为 $\mathrm{S}$ ) 只允许少 数小型土壤动物 (部分原生动物和线虫类) 进人, 孔径为 $4.5 \mathrm{~mm}$ 的调落物网袋 (标记为 $\mathrm{L}$ ) 允许所有大型、中 型和小型土壤动物进出 ${ }^{[22]}$. 每种植物调落物样品各装 15 袋, 每袋中调落物干重 $15 \mathrm{~g}$. 本研究于 2017 年 12 月将做好标记的调落物袋放人对应的样带中, 每种调落物袋放置在每种植物本来的生长区域. 实验中预计 回收 3 次调落物袋, 但为防止意外损失, 每个样地各放 5 组调落物袋. 所有调落物袋贴近地面并进行简单固 定, 尽量使其与土壤表面完全接触. 调落物分解期间共回收样品 3 次, 回收时间分别在布样后的第 $1 、 90$ 和 165 天, 实验期间所有样地均未受到水淹影响. 在按照时间梯度回收调落物袋的同时,采集调落物袋下土壤 样品: 将凋落物下方土壤表面的植被清理干净, 再沿调落物下方土壤剖面 $0 \sim 10 \mathrm{~cm}$ 深度进行土壤样品采集, 将采集的土壤样品分装于标记好的无菌聚乙烯自封袋中, 置于低温箱中迅速运回实验室.

调落物样品采集回实验室后, 将样品中石块、动植物残体去除, 用无菌水清洗表面泥土, 然后进行剩余 干物质量测定. 之后部分样品进行烘干和研磨, 过 60 目篎, 用于测定其碳、氮和磷等理化参数. 调落物下土 壤同样经过干燥、研磨和过笁以后, 进行碳、氮和磷等参数的测定.

\section{2 实验方法}

调落物下土壤样品与调落物样品理化性质测定的方法基本相同, 采用烘干法测定样品的含水量, 利用 马弗炉高温 $\left(500^{\circ} \mathrm{C}\right.$ ) 烘烤法测定去灰分干重 $(A F D M)$, 采用 $\mathrm{K}_{2} \mathrm{Cr}_{2} \mathrm{O}_{7}$ 容量法一外加热法测定总有机碳 ( TOC) 含量; 采用浓硫酸混合催化法消煮, 凯氏定氮法测定总氮 ( TN) 含量, 采用钒钿黄吸光光度法测定总磷 $(\mathrm{TP})$ 含量 ${ }^{[23-25]}$. 通过测定不同时间段调落物样品含水量, 以求得调落物经过分解后剩余的质量, 从而计算出不同 样地调落物样品的分解速率.

\section{3 数据处理}

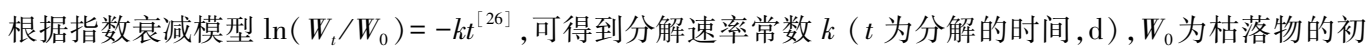
始量, $W_{t}$ 为经 $t$ 天分解后枯落物的剩余量). 植物分解过程中元素的积累或释放可用积累系数 (NAI) 表示: $N A I=\left(W_{t} \times X_{t}\right) /\left(W_{0} \times X_{0}\right) \times 100 \%$, 式中, $W_{t}$ 为植物在 $t$ 时刻的干物质重量, $X_{t}$ 为 $t$ 时刻植物中元素的含量 $(\mathrm{g} /$ $\mathrm{kg}), W_{0}$ 为植物的初始干物质重量, $X_{0}$ 为植物中元素的初始含量 $(\mathrm{g} / \mathrm{kg})$.

利用 Excel 2010 软件对数据进行图表绘制; 利用 SPSS 20.0 软件对数据进行显著性和相关性分析, 分别 对不同类型的样地中调落物分解速率和营养元素化学计量进行相关性双变量分析, 对土壤碳、氮、磷的积累 值进行单因素方差分析 (ANOVA) 和 Tukey 检验, 对不同样地类型且不同网孔大小的调落物分解速率进行一 般线性模型中的单变量多因素的相关性分析 (Pearson).

\section{2 结果与分析}

\section{1 调落物剩余干物质量的动态变化与调落物分解速率}

植物调落物分解过程中剩余干物质量的变化如图 1 所示. 3 种植物的调落物随着分解时间的增长, 干物 质剩余量均呈现下降趋势. 调落物袋网孔的大小对调落物干物质剩余量有明显的影响, 表现为大网孔 (L) 调 落物袋中干物质剩余量小于小网孔调落物袋 $(\mathrm{S})$ 中的干物质剩余量 $(P<0.05)$. 苔草、南荻、芦苇 3 种调落物 在后期 (第 90 165 天) 的分解速率普遍大于初期 (第 1 90 天) 的分解速率. 经过 165 天的分解, 苔草干物质 剩余量小于芦苇和南狄样品. 其中, 苔草 $\mathrm{L}$ 的干物质剩余量为 $51.98 \%$, 苔草 $\mathrm{S}$ 的干物质剩余量为 $55.39 \%$. 南 荻 $\mathrm{L}$ 的干物质剩余量为 $61.53 \%$, 南荻 $\mathrm{S}$ 的干物质剩余量为 $68.12 \%$. 芦苇 $\mathrm{L}$ 的干物质剩余量为 $59.48 \%$, 芦苇 $\mathrm{S}$ 的干物质剩余量为 $68.77 \%$.

不同网孔的调落物袋对调落物分解速率的影响如图 2 所示. 实验结果表明苔草、南荻和芦苇 3 种调落 物经过 165 天的分解后, 南荻和芦苇调落物大、小网孔分解袋之间分解速率有显著差异 $(P<0.05)$, 但是苔草 差异不显著 $(P>0.05)$. 苔草、南荻和芦苇调落物在大网孔调落物袋的分解速率均大于在小网孔调落物袋的 分解速率. 在 3 种不同类型的调落物之间分解速率有差异, 表现为苔草调落物的分解速率显著大于南荻、芦 苇调落物的分解速率 $(P<0.05)$, 南荻与芦苇调落物分解速率差异不明显 $(P>0.05)$.

\section{2 调落物分解过程中营养元素含量的动态变化}

植物调落物分解过程中 TOC 含量的变化如图 3a 所示. 在分解过程中, 苔草 L 和苔草 S 的 TOC 含量在 


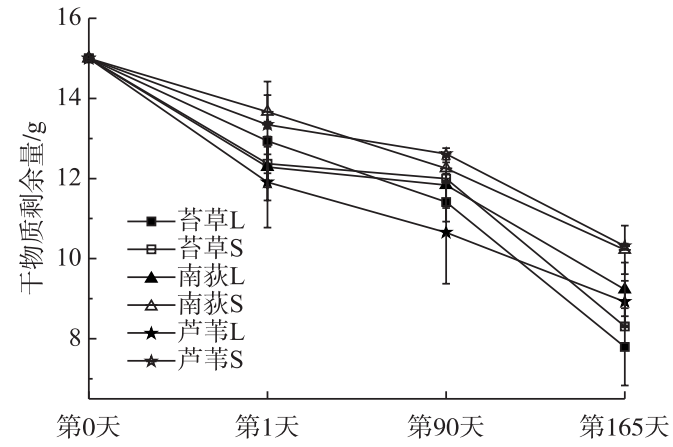

图 1 调落物分解过程中干物质 剩余量的动态变化

( $\mathrm{L}$ 代表孔径为 $4.5 \mathrm{~mm}$ 的调落物袋, $\mathrm{S}$ 代表孔径为 $0.1 \mathrm{~mm}$ 的调落物袋)

Fig. 1 The dynamics of litter remained dry mass during decomposition ( $\mathrm{L}$ stands for the litter bags with $4.5 \mathrm{~mm}$ mesh, $\mathrm{S}$ stands for the litter bags with $0.1 \mathrm{~mm}$ mesh)

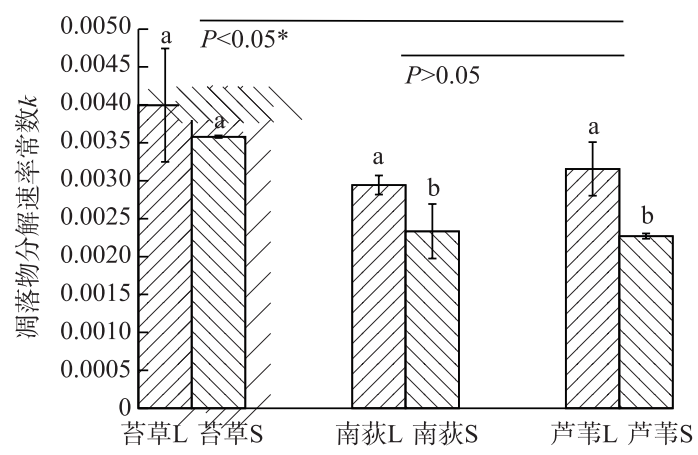

图 2 不同网孔的调落物袋对调落物分解速率的影响 (图中不同字母表示差异显著 $(P<0.05)$, 误差条 代表标准误差 $(S E)$, 图上方标注为组间均值比较)

Fig. 2 Effects of mesh size of litter bags on the litter decomposition rates( The different letters upon the bar mean significant difference among bars $(P<0.05)$, and the error bar stands for standard error $(S E)$,

The upper lines stand for mean comparison among groups)

第 90 天时差异较大, 但在第 165 天时, 其含量十分相近. 南荻 L 和南荻 S 前期 TOC 含量变化几乎保持一致; 在后期的分解过程中南荻 L 的 TOC 含量大于南荻 S 的 TOC 含量. 芦苇 L 的 TOC 含量始终大于芦苇 S 的 TOC 含量, 而且其变化趋势很相似. 总体而言, 3 种调落物的 TOC 含量随着分解的进行都呈下降的趋势, 且 分解前期 (第 1 90 天) TOC 释放速率普遍大于实验后期 (第 90 165 天). 苔草 S 在分解前、后期的 TOC 含 量减少趋势保持一致, 苔草 L 的 TOC 含量在分解前期减少速率较大, 后期不减反增. 南荻 L 和南荻 S 的 TOC 含量在分解前期都在减少, 但在分解后期南荻 S 继续减少, 南荻 L 开始增加. 芦苇 L、芦苇 S 的 TOC 含量变 化相似, 在分解前期的含量降低较快. 从这 3 种调落物的分解过程也可以看出, 苔草的初始 TOC 含量最高, 分解过程中含量降低也最快; 芦苇的 TOC 含量最低, 分解过程中的含量变化最小.
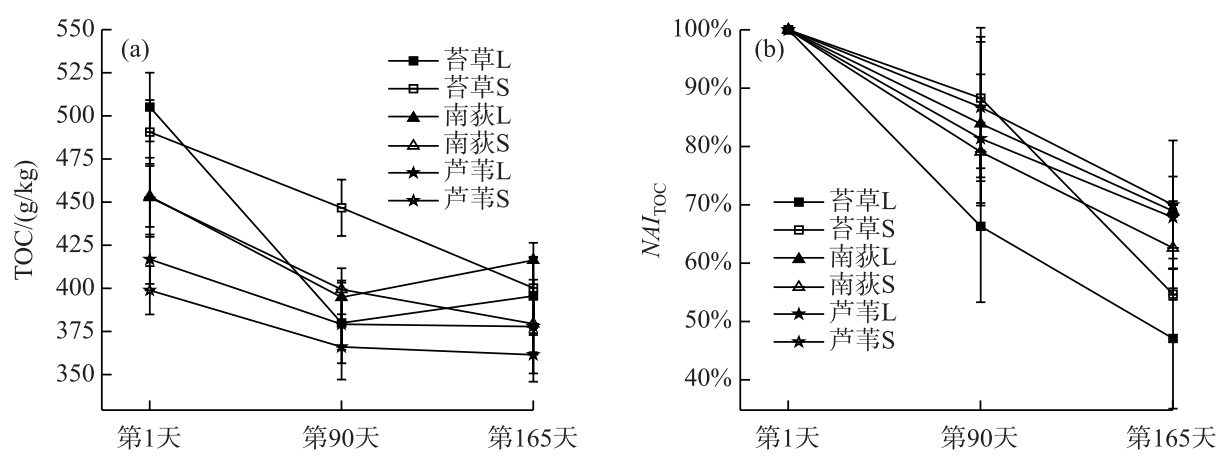

图 3 植物调落物 TOC 含量 $(\mathrm{a})$ 以及 $N A I_{\mathrm{TOC}}$ 值 $(\mathrm{b})$ 的变化

Fig. 3 The variation of TOC content (a) and $N A I_{\mathrm{TOC}}$ value (b) of plant litters

不同调落物 TOC 的积累系数 (NAI 值) 变化如图 $3 \mathrm{~b}$ 所示. 从图中可以看出, 在整个分解过程中 3 种调落 物 TOC 都是净释放的. 苔草 $\mathrm{L}$ 的 $N A I_{\mathrm{TOC}}$ 值始终小于苔草 $\mathrm{S}$ 的 $N A I_{\mathrm{TOC}}$ 值, 表明苔草在大网孔调落物袋中损失 更快. 芦苇 $\mathrm{L}$ 和芦苇 $\mathrm{S}$ 的 $N A I_{\mathrm{TOC}}$ 值在分解了 165 天后, 几乎无明显差异. 南荻 $\mathrm{L}$ 的 $N A I_{\mathrm{Toc}}$ 值则始终大于南荻 $\mathrm{S}$, 与苔草样品的结果正好相反. 实验中 3 种植物调落物经过 165 天的分解之后, $N A I_{\mathrm{TOC}}$ 的平均值表现出苔 
草 $<$ 南荻<芦苇的规律.

调落物 TN 含量变化的结果如图 4 所示. 研究结果表明, 3 种调落物 TN 含量整体呈下降趋势. 整个分解 过程中南荻 $\mathrm{L}$ 和南荻 $\mathrm{S}$ 的 TN 含量变化规律一致, 而苔草 $\mathrm{L}$ 的 TN 含量始终高于苔草 $\mathrm{S}$ 的 TN 含量. 芦苇 $\mathrm{L}$ 实验前期的 TN 含量低于芦苇 $\mathrm{S}$ 的 TN 含量, 到了后期, 芦苇 L 的 TN 含量开始增加, 甚至超过了芦苇 $\mathrm{S}$ 的 TN 含量 (图 4a). 总体来看, 3 种调落物的 TN 含量在分解前期 ( $0 \sim 90$ 天) 下降较快, 后期下降较慢. 调落物 TN 含量具有明显的物种差异, 3 种调落物的 TN 含量呈苔草>芦苇>南荻的趋势.

与初始值相比, 3 种调落物的 $N A I_{\mathrm{TN}}$ 值都降低了 (图 4b). 所有苔草样品的 $N A I_{\mathrm{TN}}$ 值在分解前、后期的变化 速率相似, 实验结束时的 $N A I_{\mathrm{TN}}$ 值也几乎一致. 南荻 $\mathrm{S}$ 样品在分解前期 $N A I_{\mathrm{TN}}$ 值减少速率大于南荻 $\mathrm{L}$, 后期两 者减少速率相近, 所以最终南荻 $\mathrm{S}$ 样品的 $N A I_{\mathrm{TN}}$ 小于南荻 $\mathrm{L}$. 芦苇 $\mathrm{L}$ 样品在分解前期 $N A I_{\mathrm{TN}}$ 值减少速率大于芦 苇 $\mathrm{S}$, 但在后期不减反增, 而芦苇 $\mathrm{S}$ 样品持续减少, 所以最后芦苇 $\mathrm{L}$ 的 $N A I_{\mathrm{TN}}$ 大于芦苇 $\mathrm{S}$. 从 3 种凋落物样品 的比较来看, 南狄样品的总氮释放量最小, 苔草样品的释放量最大. 从调落物袋网孔大小的比较来看, 大网 孔 L 的总氮损失小于小网孔 $S$.
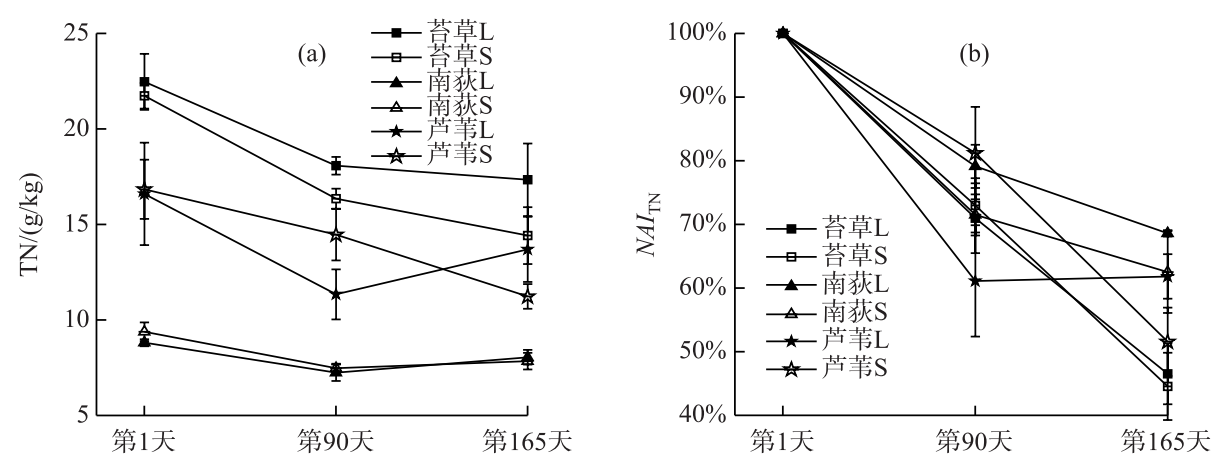

图 4 植物凋落物 $\mathrm{TN}$ 含量 $(\mathrm{a})$ 以及 $N A I_{\mathrm{TN}}$ 值 $(\mathrm{b})$ 的变化

Fig.4 The variation of TN content (a) and $N A I_{\mathrm{TN}}$ value (b) of plant litters

调落物 TP 含量随分解时间变化的结果如图 5 所示, 3 种调落物的 TP 含量整体上呈现出分解前期稳定 后期增加的趋势. 在分解前期, 芦苇 L 与芦苇 S 的 TP 含量相近, 但在之后的分解过程中, 芦苇 L 的 TP 含量 始终小于芦苇 $\mathrm{S}$ 的 TP 含量; 实验结束时, 两者含量又处于同一水平. 分解前期南荻 L 的 TP 含量大于南荻 $\mathrm{S}$, 分解后期因南荻 $\mathrm{S}$ 的 TP 含量增长较快, 导致最终南荻 S 的 TP 含量大于南荻 L. 苔草 L 和苔草 $\mathrm{S}$ 的 TP 含 量在整个过程中比较相近 (图 5a). 3 种植物调落物大网孔样品的 $N A I_{\mathrm{TP}}$ 值都要小于小网孔的 $N A I_{\mathrm{TP}}$ 值. 以分 解第 90 天作为临界点, 分解前期 6 组样品的 $N A I_{\mathrm{TP}}$ 值都在减小, 后期 6 组样品的 $N A I_{\mathrm{TP}}$ 值都在增加 (图 $5 \mathrm{~b}$ ).

调落物分解过程中 $\mathrm{C}: \mathrm{N}$ 比的变化具有明显的物种差异 (图 6a), 南荻 $\mathrm{C}: \mathrm{N}$ 比最大, 其次是芦苇和苔草. 实验结束时, 苔草 $\mathrm{L}$ 的 $\mathrm{C}: \mathrm{N}$ 比变化不明显, 苔草 $\mathrm{S}$ 的 $\mathrm{C}: \mathrm{N}$ 比增大. 南荻样品 $\mathrm{C}: \mathrm{N}$ 比的初始值与最终值无明 显差异. 芦苇样品的 $\mathrm{C}: \mathrm{N}$ 比增大, 且芦苇 $\mathrm{S}$ 的 $\mathrm{C}: \mathrm{N}$ 比大于芦苇 $\mathrm{L}$ 的 $\mathrm{C}: \mathrm{N}$ 比.

调落物 $\mathrm{N}: \mathrm{P}$ 比也有明显物种差异 (图 6b), 不同样品初始的 $\mathrm{N}: \mathrm{P}$ 比差异明显, 表现为苔草>芦苇>南荻. 经过 165 天的分解, 不同样品的 $\mathrm{N}: \mathrm{P}$ 比趋于相似. 分解初始时, 所有样品的 $\mathrm{N}: \mathrm{P}$ 比都是小网孔袋较高; 而在 分解结束时, 所有样品的 $\mathrm{N}: \mathrm{P}$ 比都是大网孔袋较高. 在分解的阶段上, 分解前期凋落物的 $\mathrm{N}: \mathrm{P}$ 比无太大的 变化,分解后期 3 种植物调落物 $N: P$ 比都明显降低.

\section{3 调落物分解对土壤养分归还的影响}

调落物分解对土壤 $N A I_{\mathrm{TOC}}$ 值的影响 (图 7A) 结果表明, 经过 165 天的分解之后, 苔草 $\mathrm{S}$ 样品下土壤的 $N A I_{\mathrm{TOC}}$ 值显著大于对应的大网孔下土壤样品的 $N A I_{\mathrm{Toc}}$ 值 $(P<0.05)$, 南荻 $\mathrm{L}$ 样品下土壤的 $N A I_{\mathrm{TOC}}$ 值大于对应 的小网孔下土壤样品的 $N A I_{\mathrm{TOC}}$ 值 $(P<0.05)$, 芦苇样品下对应土壤的 $N A I_{\mathrm{TOC}}$ 值在大、小网孔之间也有差异, 但 是不显著. 除南荻 $\mathrm{S}$ 样品下土壤的 $N A I_{\mathrm{roc}}$ 值略小于空白之外, 其余调落物样品下土壤样品的 $N A I_{\mathrm{roc}}$ 值都大于 空白. 调落物分解后, 根据土壤表面的调落物类型不同, 对应土壤有机碳的积累能力也不同, 总体表现为芦 

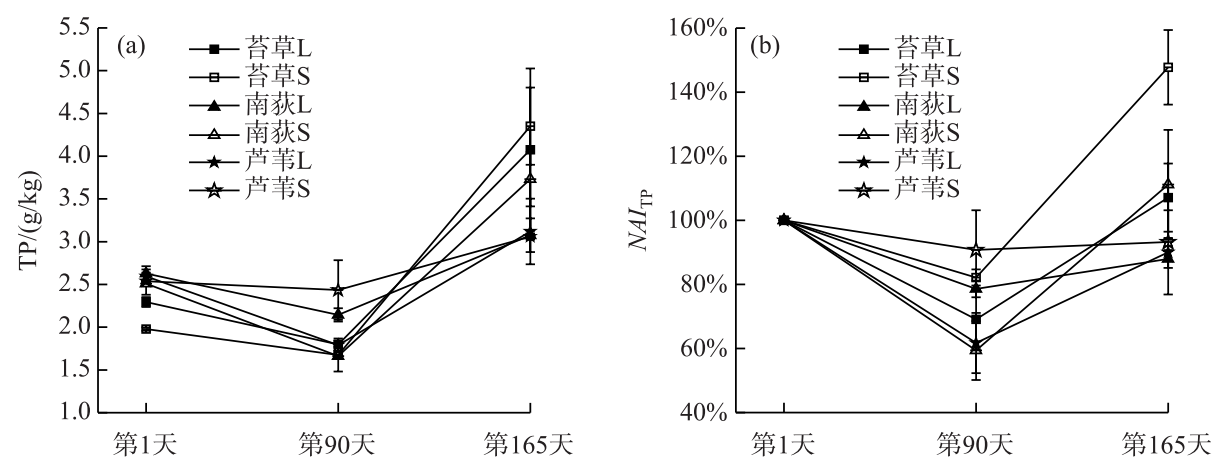

图 5 植物调落物 $\mathrm{TP}$ 含量 $(\mathrm{a})$ 以及 $N A I_{\mathrm{TP}}$ 值 $(\mathrm{b})$ 的变化

Fig.5 The variation of TP content (a) and $N A I_{\mathrm{TP}}$ value (b) of plant litters

苇>苔草>南荻.
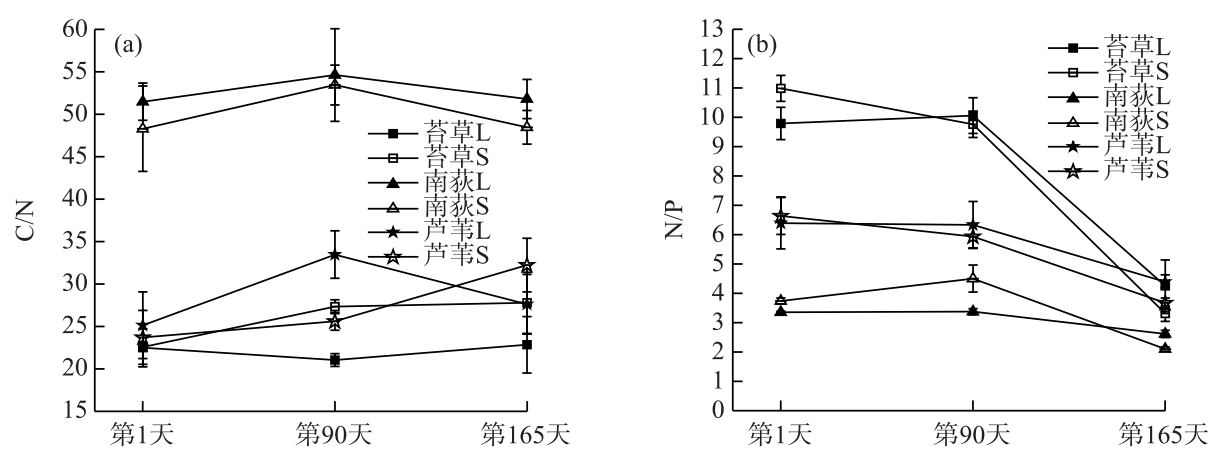

图 6 不同植物调落物 $\mathrm{C}: \mathrm{N}$ 比 $(\mathrm{a})$ 及 $\mathrm{N}: \mathrm{P}$ 比 $(\mathrm{b})$ 的动态变化

Fig.6 The variation of $\mathrm{C}: \mathrm{N}$ ( a ) and $\mathrm{N}: \mathrm{P}$ ratios (b) of different plant litters

调落物分解对土壤的 $N A I_{\mathrm{TN}}$ 值的影响 (图 7B) 结果表明, 苔草 $\mathrm{S}$ 、南荻 $\mathrm{S}$ 和芦苇 $\mathrm{L} 165$ 天的分解过程显著 提高了土壤中 $\mathrm{TN}$ 含量 $(P<0.05)$, 而苔草 $\mathrm{L}$ 和芦苇 $\mathrm{S}$ 的分解过程也有利于土壤中 $\mathrm{TN}$ 的积累. 不同孔径的 调落物袋对土壤中 TN 积累的影响因调落物种类而异, 对于苔草和芦苇没有显著影响, 但对于南狄影响显著 $(P<0.05)$. 根据土壤表面的调落物类型不同, 对应土壤 TN 的积累能力也不同, 总体表现为苔草 $>$ 芦苇 $>$ 南荻.

调落物分解对土壤 $N A I_{\mathrm{TP}}$ 值的影响 (图 7C) 结果表明, 苔草 $\mathrm{S}$ 样品下土壤的 $N A I_{\mathrm{TP}}$ 值显著大于对应的大 网孔的 $N A I_{\mathrm{TP}}$ 值 $(P<0.05)$, 芦苇 $\mathrm{L}$ 样品下土壤的 $N A I_{\mathrm{TP}}$ 值显著大于对应的小网孔的 $N A I_{\mathrm{TP}}$ 值 $(P<0.05)$, 南 荻样品下对应土壤的 $N A I_{\mathrm{TP}}$ 值在大、小网孔之间也有差异, 但是不显著. 除芦苇 $\mathrm{S}$ 之外, 其余调落物样品都显 著增加了土壤 TP 含量 $(P<0.05)$. 根据土壤表面的调落物类型不同, 对应土壤 TP 的积累能力表现为南荻> 苔草>芦苇.

\section{4 调落物分解速率与营养元素归转的相关性分析}

通过分析调落物的分解速率与调落物营养元素的释放、土壤中营养元素的积累的相关性 (表 1) 可知: 苔 草 $\mathrm{L}$ 的分解速率与残余调落物质量呈显著负相关 $(P<0.05)$. 苔草 $\mathrm{S}$ 的分解速率与调落物 $\mathrm{TP}$ 含量以及 $N A I_{\mathrm{TP}}$ 值呈显著正相关 $(P<0.01)$, 与调落物的 $N A I_{\mathrm{TOC}} 、 N A I_{\mathrm{TN}}$ 值呈显著负相关 $(P<0.01)$, 与 $\mathrm{N}: \mathrm{P}$ 比呈显著负相关, 与残余调落物质量呈显著负相关 $(P<0.01)$, 与土壤 $\mathrm{TP}$ 含量呈显著正相关 $(P<0.05)$. 南荻 $\mathrm{L}$ 的分解速率与 土壤的 $N A I_{\mathrm{TP}}$ 值呈显著正相关 $(P<0.05)$. 在此研究中没有发现南荻 $\mathrm{S}$ 与芦苇 $\mathrm{L}$ 的分解速率与其他的营养元 素有相关性. 芦苇 $\mathrm{S}$ 的分解速率与调落物 TP 含量呈显著正相关 $(P<0.01)$, 与 $\mathrm{N}: \mathrm{P}$ 比呈显著负相关 $(P<$ 
$0.01)$, 与残余调落物质量呈显著负相关 $(P<0.01)$,与土 壤 TN 含量呈显著负相关 $(P<0.05)$. 纵观 6 组调落物样 品的分解速率与营养元素的关系, 可以看出调落物的分 解速率与调落物 $N A I_{\mathrm{TOC}} 、 N A I_{\mathrm{TN}}$ 值和残余调落物质量呈负 相关.

\section{3 讨论}

\section{1 土壤动物对调落物分解速率的影响}

使用不同网孔直径的分解袋有效地限制了不同体 型土壤动物的进出, $4.5 \mathrm{~mm}$ 孔径的调落物袋可以允许全 部的小型土壤动物和大部分中型土壤动物 (体宽 $100 \mu \mathrm{m} \sim 2 \mathrm{~mm}$ ) 进人, $0.1 \mathrm{~mm}$ 孔径的调落物袋仅允许部 分小型土壤动物 (体宽 $2 \sim 100 \mu \mathrm{m}$ ) 进人. 本实验中苔 草 $\mathrm{L}$ 、苔草 $\mathrm{S}$ 、南荻 $\mathrm{L}$ 、南荻 $\mathrm{S}$ 、芦苇 $\mathrm{L}$ 、芦苇 $\mathrm{S}$ 六组调落物 样品的分解速率结果表明, 大网孔调落物袋中的调落物 分解速率大于小网孔调落物袋中的调落物分解速率. 这 与前人研究结果相似, 说明大、中型土壤动物的加人能 够促进调落物的分解 ${ }^{[27-28]}$. 中型土壤动物对调落物进行 物理破碎, 能有效增大凋落物的表面积, 从而增加微生 物对调落物的利用率, 还能使土壤动物食用调落物后产 生的碎屑从网孔中掉落,这两者都会增大调落物的分解 速率 ${ }^{[29]}$. 虽然调落物破碎、淋溶会因不同的网孔大小造 成调落物质量损失有差异, 但 Bokhorst 等 ${ }^{[30]}$ 的研究表明 在没有土壤动物的情况下, 调落物的质量损失不会因网 孔大小而有显著差异,这表明使用不同的网孔不会对质 量损失产生直接影响, 所以仍然将淋溶与破碎产生的质 量损失归结为土壤动物的作用. 土壤动物消耗和破坏调 落物, 并通过粪便的产生能够刺激微生物群落的繁殖进 而促进调落物的分解 ${ }^{[31]}$. 虽然中型土壤动物群还会以 微生物为食, 从而对微生物群落结构产生影响, 来影响 调落物的分解, 但整体上还是会增大调落物的分解速 率 $^{[22]}$. 尽管冬季低温会使一些土壤动物休眠, 但仍然会 有一些耐寒的土壤动物活动, 并对调落物的分解尤其是 木质素和纤维素等难分解物质的分解产生重要作用, 也 影响调落物腐殖质化的过程 ${ }^{[32-34]}$.

在整个分解过程中, 第 1 天调落物的分解速率最大, 可能原因是早期凋落物中含有较多的易溶性物质 和无机盐, 主要靠淋溶分解调落物; 随着时间的增长, 易溶性物质减少, 剩余的难溶性物质增多, 于是分解速 ${ }^{\text {率变慢 }}{ }^{[35]}$. 但从整个分解周期来看, 苔草、南荻、芦苇 3 种调落物在后期 (第 90 165 天) 的平均分解速率普 遍大于初期 (第 1 90 天), 这与之前的报道结果不同. 本研究中调落物分解的初期 (第 1 90天) 处于 $12-2$ 月份, 这个时间段的温度为一年之中最低, 这种条件下的土壤生物活性低, 对凋落物分解的贡献减弱, 调落 物分解此时受环境条件影响较大 ${ }^{[28]}$. 分解后期 (第 90 165 天) 处于 3-5 月份, 温度逐渐升高, 为各种土壤 生物进行正常的生命活动提供了良好的环境条件, 调落物的分解速率便加快 ${ }^{[5]}$.

\section{2 调落物的基质质量对分解速率的影响}

不同的物种之间, 调落物基质质量对分解速率的快慢起主要作用 ${ }^{[36]}$. 苔草调落物的分解速率显著大于
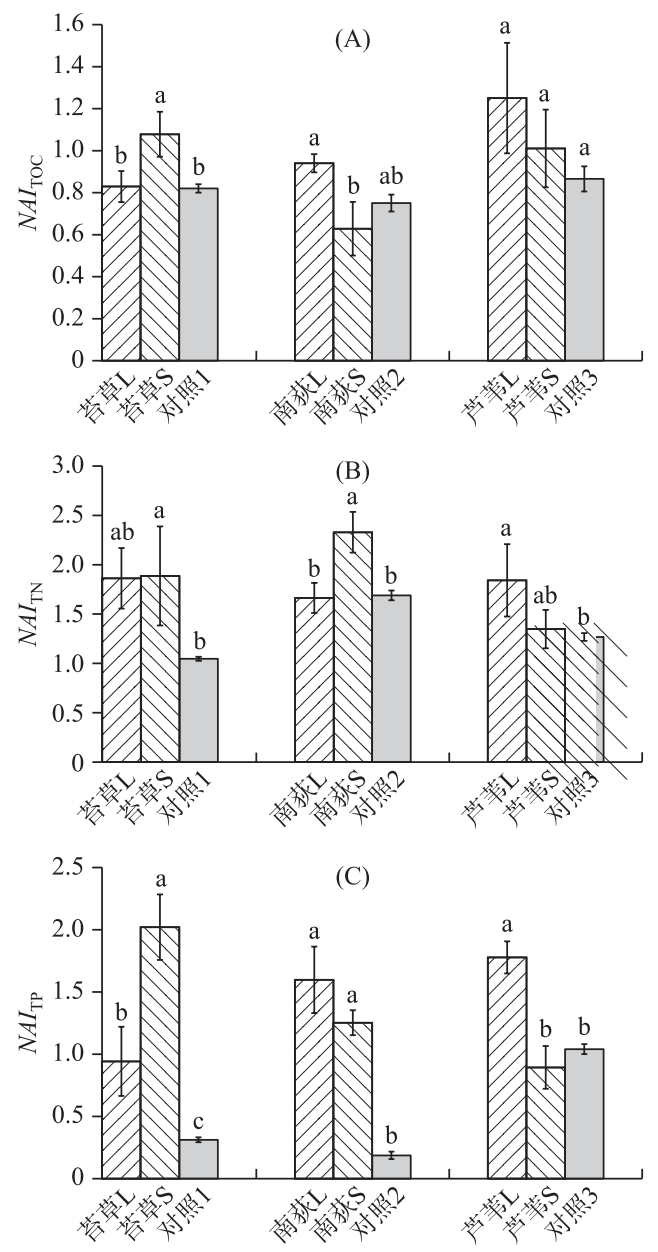

图 7 调落物分解对土壤 $N A I_{\mathrm{TOC}}(\mathrm{A}) 、 N A I_{\mathrm{TN}}(\mathrm{B})$ 和 $N A I_{\mathrm{TP}}(\mathrm{C})$ 值的影响(不同字母代表 组内比较误差显著 $(P<0.05))$

Fig.7 The effects of litter decomposition on soil $N A I_{\mathrm{TOC}}(\mathrm{A}), N A I_{\mathrm{TN}}(\mathrm{B})$ and $N A I_{\mathrm{TP}}(\mathrm{C})$ values (Different letters stand for significant difference within group $(P<0.05))$ 
表 1 不同样品分解速率与调落物及土壤中营养元素化学计量间的相关性分析

Tab.1 Correlation analysis between decomposition rates of different samples and the stoichiometry of litter and soil nutrient elements

\begin{tabular}{|c|c|c|c|c|c|c|c|c|c|c|}
\hline$k$ & P-TP-C & $\mathrm{P}-N A I_{\mathrm{TOC}}$ & $\mathrm{P}-N A I_{\mathrm{TN}}$ & $\mathrm{P}-N A I_{\mathrm{TP}}$ & $\mathrm{C}: \mathrm{N}$ & $\mathrm{N}: \mathrm{P}$ & M & S-TN-C & S-TP-C & $\mathrm{S}-N A I_{\mathrm{TP}}$ \\
\hline 苔草 L & 0.731 & -0.739 & -0.743 & 0.679 & 0.434 & -0.787 & $-0.882 *$ & -0.678 & 0.308 & 0.387 \\
\hline 苔草 S & $0.979^{* *}$ & $-0.972^{* * *}$ & $-0.975^{* *}$ & 0.970 ** & 0.705 & $-0.999^{\text {** }}$ & $-0.997^{* *}$ & 0.063 & $0.885^{*}$ & 0.697 \\
\hline 南荻 L & 0.502 & -0.752 & -0.180 & 0.653 & -0.618 & -0.400 & -0.646 & 0.405 & 0.787 & 0.826 * \\
\hline 南荻 S & 0.128 & -0.434 & -0.415 & -0.042 & 0.254 & -0.236 & -0.496 & 0.320 & 0.196 & 0.390 \\
\hline 芦苇 L & -0.397 & -0.071 & -0.743 & -0.589 & -0.044 & 0.755 & -0.320 & -0.099 & 0.015 & 0.033 \\
\hline 芦苇 S & $0.981^{* *}$ & -0.786 & -0.769 & 0.529 & 0.726 & -0.955 *** & $-0.944^{* *}$ & $-0.854 *$ & -0.624 & -0.628 \\
\hline
\end{tabular}

* 表示在 0.05 水平 (双侧) 上显著相关; ** 表示在 0.01 水平 (双侧) 上显著相关. P-TP-C 代表了调落物中 TP 含量; S$N A I_{\mathrm{TP}}$ 代表了土壤中总磷的 $N A I$ 值; $\mathrm{M}$ 代表了调落物干物质剩余量.

南荻、芦苇调落物的分解速率 $(P<0.05)$. 南荻调落物初始的 $\mathrm{C}: \mathrm{N}$ 比在 3 种调落物中最大, 分解速率却比较 慢,有研究表明,初始 $\mathrm{C}: \mathrm{N}$ 比较大的调落物分解速率反而较慢 ${ }^{[37]}$. 这 3 种调落物中,苔草调落物分解速率最 快, 初始 $C: N$ 比最小, $N: P$ 比最大, 并且苔草调落物 $N$ 含量一直处于最大值. 由此可以得出, 氮为调落物分 解过程中的限制性元素, 需要分解者从外界环境固定, 才能维持较快的分解速率 ${ }^{[38]}$. Lee 等 ${ }^{[39]}$ 研究结果也表 明 $\mathrm{C}: \mathrm{N}$ 比是调落物分解率变化的重要预测因子.

\section{3 调落物分解过程对于土壤养分的影响}

调落物分解过程中会释放营养元素, 土壤动物和微生物为了维持正常的生命活动会同化营养元素,所 以营养元素不会随着调落物的分解一直下降, 而是处于由调落物分解释放和微生物固定两者综合的动态变 化之中 ${ }^{[40]}$. 微生物维持正常的生命活动所需要的 $\mathrm{N}$ 是一定的, 所以当调落物本身 $\mathrm{N}$ 含量不高, 微生物就会 从外界固定 $\mathrm{N}^{[41]}$. 南荻的初始 $\mathrm{C}: \mathrm{N}$ 比较高, 所以在分解过程中, 微生物需要从外界固定 $\mathrm{N}$ 才能维持微生物 的正常活动, 所以才会造成南荻调落物在后期 $\mathrm{N}$ 含量增加的结果. 苔草 $\mathrm{S}$ 、南荻 $\mathrm{S}$ 、芦苇 $\mathrm{L}$ 对土壤 $\mathrm{TN}$ 的积累 有显著影响 $(P<0.05)$, 说明调落物分解能够有效地引起土壤 $\mathrm{TN}$ 的积累, 并且还与调落物种类有关, 这与余 琴等 ${ }^{[27]}$ 的研究结果相同. 土壤动物对于调落物营养释放的影响是多方面的, 不仅能够通过摄食和排泄影响 调落物营养元素的释放, 还能够通过改变土壤结构和性质、调节微生物群落结构影响土壤养分元素的归还 过程,但对于不同的调落物其表现并不相同 ${ }^{[42]}$.

苔草调落物初始 TOC 含量最高, 芦苇调落物初始 TOC 含量最低, 这与吴琴等 ${ }^{[43]}$ 的研究结果是相同的. 芦苇的 TOC 含量始终处于三者当中最低, 从 $N A I_{\mathrm{TOC}}$ 值变化可以看出芦苇的积累值最大, 释放的最少. 以往研 究表明伴随着调落物的分解, 调落物木质素的分解速率与调落物中可溶性有机碳含量呈正相关 ${ }^{[44]}$. 实验前 期测得芦苇相对于南荻、苔草的木质素含量较高, 而木质素降解速率较慢, 残余较多难溶性有机碳导致有机 碳释放较少. 分解后期养分的释放速率减慢, 有些养分含量也开始增大, 尤其发生在拥有较多土壤动物的大 网孔分解袋中. 可能原因是分解前期养分充足, 足以维持分解者的正常生物功能, 经微生物分解将调落物的 养分释放到外界环境中, 养分含量降低较快, 分解后期养分不再充足, 养分便富集在调落物中, 而大网孔中 土壤动物数量更多, 对养分含量的影响更大 ${ }^{[45]}$. 实验结果表明调落物分解有利于于促进土壤 TOC 含量的积 累, 而土壤动物在其中起着重要作用 ${ }^{[46]}$.

调落物 TOC 和 TN 含量在分解过程中整体都呈现下降的趋势, 然而实验结束后 6 组调落物样品 TP 含 量明显增加, 这与调落物样品中 TOC、TN 含量变化趋势是相反的. 微生物所需要的营养元素 $(\mathrm{N} 、 \mathrm{P})$ 一般高 于调落物本身的营养元素的含量, 微生物为了维持正常的生命活动需要从外界固定营养元素, 因此磷也是 限制性元素 ${ }^{[46-47]}$. 多数样品在实验前期 (第 1 90 天) 经过淋溶, P 含量减少到最低值后, 后期 (第 $90 \sim 165$ 天) 通过微生物固定的作用 $\mathrm{P}$ 含量开始增加. 最后一次采样测得 3 种植物调落物大网孔样品 $N A I_{\mathrm{TP}}$ 值都要小 于小网孔的 $N A I_{\mathrm{TP}}$ 值, 说明土壤动物对调落物总磷的释放有促进作用. 有研究 ${ }^{[36]}$ 表明土壤动物对于调落物氮 释放的影响更多是取决于调落物的物种差异, 而对磷释放的影响更多是取决于气候条件, 这与本研究的结 论相似. 


\section{4 结论}

综上所述, 本研究揭示了湖泊湿地中典型植物凋落物 (苔草、南荻和芦苇) 的分解规律, 以及土壤动物对 于凋落物分解的影响,这些研究结果有助于我们理解湖泊湿地中碳、氮、磷等营养元素的周转过程, 也有利 于科学地评估和预测湿地植被的演化进程以及湿地生态系统的健康状态. 总体来看, 苔草调落物中较高的 氮和磷含量、较低的木质素和纤维素含量有利于快速分解, 也有利于营养元素向土壤的输送 (特别是氮和 磷); 但是相较于其它调落物样品, 苔草下土壤中氮、磷元素含量较低, 表明苔草分解过程中营养元素的周转 速率较快. 南狄和芦苇调落物的分解能够明显提高土壤中的 TN 含量, 芦苇能够明显提高土壤中的 TP 含量. 尽管土壤动物对不同调落物分解的影响各不相同, 但总体上还是可以看出大网孔调落物袋样品及其土壤中 $\mathrm{TN}$ 含量均高于对应小网孔袋样品, 但总磷含量低于对应小网孔袋样品, 这表明土壤动物有利于维持调落物 中的总氮含量以及土壤中氮的积累, 但会削弱分解相关微生物的聚磷效果以及土壤中磷的积累. 此外, 由于 本研究采用的调落物袋排除了大型土壤动物的影响, 会导致我们低估土壤动物在调落物分解中的贡献.

\section{5 参考文献}

[ 1 ] Zhang XH, Gong C. Research advances in standing litter decomposition of emergent macrophyte in Wetlands. Ecology and Environmental Sciences, 2013, 22(4) : 712-717. [张新厚, 宫超. 湿地挺水植物调落物立枯分解研究进展. 生态环境 学报, 2013, 22(4): 712-717.]

[ 2 ] Gorham E. Northern peatlands: role in the carbon cycle and probable responses to climatic warming. Ecological Applications, 1991, 1(2) : 182-195.

[ 3 ] Scott DT, Sally AE, Gordon HR et al. Litter decomposition and associated invertebrate communities in Wetland Ponds of the Copper River Delta, Alaska (USA). Wetlands, 2013, 33(6) : 1151-1163.

[ 4 ] Tristan GR, Anderson JT. Litter decomposition in created and reference wetlands in West Virginia, USA. Wetlands Ecology and Management, 2011, 19(5): 449-458.

[ 5 ] Guan YZ, Liu AT, Zhong QC et al. Responses of decomposition of Phragmites australis litter to simulated temperature enhancement in the reclamed coastal wetland. Journal of East China Normal University: Natural Science, 2013, (5) : 27-34. [关阅章, 刘安田, 仲启铖等. 滨海围脣湿地芦苇调落物分解对模拟增温的响应. 华东师范大学学报: 自然科学 版, 2013, (5): 27-34.]

[ 6 ] Zhang XH, Tan WW, Zhang JS et al. Effects of phosphorus addition on litter quality of Deyeuxia angustifolia and the subsequent aerial decomposition in a meadow in Sanjiang Plain. Ecology and Environmental Sciences, 2018, 27 (2) : 209-215. [张新厚, 谭稳稳, 张加双等. 磷添加对三江平原湿地小叶章立枯质量和分解的影响. 生态环境学报, 2018, 27 (2) : 209-215.]

[ 7 ] Zhang L, Zeng C, Zhang W et al. Litter decomposition and its main affecting factors in tidal marshes of Minjiang River estuary, East China. Chinese Journal of Applied Ecology, 2012, 23(9): 2404-2410. [张林海, 曾从盛, 张文娟等. 闽江 河口湿地枯落物分解及主要影响因子. 应用生态学报, 2012, 23(9): 2404-2410.]

[ 8 ] Fujii S, Takeda H. Succession of soil microarthropod communities during the aboveground and belowground litter decomposition processes. Soil Biology and Biochemistry, 2017, 110: 95-102.

[ 9 ] Ma R. Study on decomposition characteristics and soil enzyme activity of litter in Gahai degraded swamp meadow wetland [Dissertation]. Lanzhou: Gansu Agricultural University, 2017. [马瑞. 尔海退化沼泽草甸湿地凋落物分解特征与土 壤酶活性研究 [ 学位论文]. 兰州: 甘肃农业大学, 2017.]

[10] Chimney MJ, Pietro KC. Decomposition of macrophyte litter in a subtropical constructed wetland in south Florida (USA). Ecological Engineering, 2006, 27(4) : 301-321.

[11] Wu H, Lu X, Jiang M et al. Impacts of soil fauna on litter decomposition at different succession stages of wetland in Sanjiang Plain, China. Chinese Geographical Science, 2009, 19(3) : 258-264.

[12] Yang B, Zhang W, Xu H et al. Effects of soil fauna on leaf litter decomposition under different land uses in eastern coast of China. Journal of Forestry Research, 2018, 29(4) : 973-982.

[13] Ma C, Yin X, Wang H. Soil fauna effect on Dryas octopetala litter decomposition in an Alpine tundra of the Changbai Mountains, China. Alpine Botany, 2019, 129: 53. https://doi.org/10.1007/s00035-018-0215-4. 
[14] Fan H, Wang SZ, Ruan HH et al. Effects of soil fauna on litter decomposition and its community structure under different land use patterns in coastal region of northern Jiangsu province. Journal of Nanjing Forestry University: Natural Science Edition, 2014, 38(3): 1-7. [范换, 王邵军, 阮宏华等. 苏北沿海不同土地类型土壤动物群落及其对调落物分解的 影响. 南京林业大学学报: 自然科学版, $2014,38(3)$ : 1-7.]

[15] Bao JL. Study on contribution of soil fauna to litter decomposition of Rhododendron chrysanthun in Betula ermanii forest on Changbai Mountain[Dissertation]. Changchun: Northeast Normal University, 2013. [包剑利. 长白山岳桦林带牛皮杜 鹃调落物分解及土壤动物的作用 [学位论文]. 长春: 东北师范大学, 2013.]

[16] González G, Seastedt TR. Soil fauna and plant litter decomposition in tropical and subalpine forests. Ecology, 2001,82 (4) : 955-964.

[17] Xin WD. Community characters and functional role in litter decomposition of soil fauna in fixed dune in Songnen sandy land [Dissertation]. Changchun: Northeast Normal University, 2011. [辛未冬. 松嫩沙地固定沙丘土壤动物群落特征及其 在调落物分解中的作用研究 [学位论文]. 长春: 东北师范大学, 2011.]

[18] Chen JZ. Dynamic of litter and carbon and nitrogen return of Keteleeria fortunei plantation. Journal of Fujian Forestry Science and Technology, 2017, 44(4) : 14-17,27. [陈金章. 油杉人工林调落物及其碳氮归还动态. 福建林业科技, $2017, \mathbf{4 4}(4): 14-17,27$.

[19] Cui HX, Pan L, Huang ZL et al. Characteristics of litter production dynamics and decomposition process of Abies fargesii forest in Shennongjia, Hubei Province. Journal of Nanjing Forestry University: Natural Science Edition, 2017, 41(1) : 194-198. [崔鸿侠, 潘否, 黄志霖等. 神农架巴山冷杉林调落物量养分归还及分解特征. 南京林业大学学报: 自然 科学版, 2017, 41(1) : 194-198.]

[20] Cui LJ, Zhao XS. Researches on the energy analysis of Poyanghu wetland. Acta Ecologica Sinica, 2004, 24 (7): 14801485. [崔丽娟, 赵欣胜. 鄱阳湖湿地生态能值分析研究. 生态学报, 2004, 24(7) : 1480-1485.]

[21] Cui LJ. Evaluation on functions of Poyang Lake ecosystem. Chinaese Journal of Ecology, 2004, 23(4) : 47-51. [崔丽娟. 鄱阳湖湿地生态系统服务功能价值评估研究. 生态学杂志, 2004, 23(4) : 47-51.]

[22] Bradford MA, Tordoff GM, Eggers T et al. Microbiota, fauna, and mesh size interactions in litter decomposition. Oikos. 2002, 99(2): 317-323.

[23] Zhang J, Yu C, Wang ZH et al. Diversity of bacterial communities in surface soils under different vegetation communities. Research of Environmental Sciences, 2013, 26(8) : 866-872. [张杰, 余潮, 王自海等. 不同植被群落表层土壤中细菌 群落多样性. 环境科学研究, 2013, 26(8): 866-872.]

[24] Ge G, Xu YH, Zhao L et al. Spatial distribution characteristics of soil organic matter and nitrogen in the Poyang Lake Wetland. Resources and Environment in the Yangtze Basin, 2010, 19(6): 619-622. [葛刚, 徐燕花, 赵否等. 鄱阳湖典型湿 地土壤有机质及氮素空间分布特征. 长江流域资源与环境, 2010，19(6): 619-622.]

[25] Chen FS, Hu X, Ge G. Leaf N:P stoichiometry and nutrient resorption efficiency of Ophiopogon japonicus in Nanchang City. Acta Prataculturae Sinica, 2007, 16(4): 47-54. [陈伏生, 胡小飞, 葛刚. 城市地被植物麦冬叶片氮磷化学计量 比和养分再吸收效率. 草业学报, 2007, 16(4): 47-54.]

[26] Olson JS. Energy storage and the balance of producers and decomposers in ecological systems. Ecology, 1963, 44(2): 322-331.

[27] Yu Q, Wu J, Liang DF et al. Effects of flooding condition and mesh size on leaf litter decomposition of the dominant species, Carex atrofusca, in an alpine swamp meadow in Tibetan Plateau. Chinese Journal of Ecology, 2015, 34(10) : 27852791. [ 余琴, 册洁, 梁德飞等. 积水和网孔大小对青藏高原高寒沼泽化草甸优势种黑褐苔草叶片调落物早期分解 的影响. 生态学杂志, 2015, 34(10): 2785-2791.]

[28] Wu HT, Lv XG, Yang Q et al. Effect of soil fauna on decomposition of litters in Carex lasiocarpa Wetland in Sanjiang Plain. Journal of Ecology and Rural Environment, 2006, 22(3): 5-10. [武海涛, 吕宪国, 杨青等. 土壤动物对三江平 原典型毛果苔草湿地枯落物分解的影响. 生态与农村环境学报, 2006, 22(3):5-10.]

[29] Xia L. Contribution of soil fauna to litter decomposition in the alpine/subalpine forests[Dissertation]. Ya'an: Sichuan Agricultural University, 2012. [夏否. 土壤动物对高山/亚高山森林调落物分解的贡献 [ 学位论文]. 雅安: 四川农业大 学, 2012.]

[30] Bokhorst S, Wardle DA. Microclimate within litter bags of different mesh size: Implications for the "arthropod effect” on litter decomposition. Soil Biology and Biochemistry, 2013, 58: 147-152. 
[31] Coleman DC, Crossley DA, Hendrix PF eds. Fundamentals of soil ecology. San Diego: Academic Press, 2004.

[32] Yu T, Yang WQ, Shu L et al. Effects of soil fauna on winter litter humification along an altitudinal gradient in cold ecosystems in western Sichuan. Acta Ecologica Sinica, 2017, 37(5) : 1595-1602. [谭羽, 杨万勤, 廖姝等. 川西高寒生态系 统不同海拔土壤动物对冬季调落叶腐殖化过程的影响. 生态学报, 2017, 37(5): 1595-1602.]

[33 ] Lifeng W, Jian Z, Runlian H et al. Impacts of soil fauna on lignin and cellulose degradation in litter decomposition across an alpine forest-tundra ecotone. European Journal of Soil Biology, 2018, 87: 53-60.

[34] Zhang Y, Zhang D, Li X et al. Contribution of soil fauna to the degradation of recalcitrant components in Cinnamomum camphora foliar litter in different-sized gaps in Pinus massoniana plantations. Journal of Forestry Research, 2018. https:// doi.org/10.1007/s11676-018-0609-6.

[35] Liu DY, Song CZ. The litter characteristics of Calamagrostis angustifolia and its early-stage decomposition affected by exogenous nitrogen input in freshwater marsh. Wetland Science, 2008, 6(2) : 235-241. [刘德燕, 宋长春. 外源氮输人对 沼泽湿地小叶章枯落物性质及其早期分解的影响. 湿地科学, 2008, 6(2) : 235-241.]

[36] Wu HT, Lv XG, Yang Q et al. The early-stage litter decomposition and its influencing factors in the wetland of the Sanjiang Plain, China. Acta Ecologica Sinica, 2007, 27 (10): 4027-4035. [武海涛, 吕宪国, 杨青等. 三江平原典型湿地 枯落物早期分解过程及影响因素. 生态学报, 2007, 27(10): 4027-4035.]

[37] Yang JS, Liu JS, Yu JB et al. Decomposition and nutrient dynamics of marsh litter in the Sanjiang Plain, China. Acta Ecologica Sinica, 2006, 26(5): 1297-1302. [杨继松, 刘景双, 于君宝等. 三江平原沼泽湿地枯落物分解及其营养动 态. 生态学报, 2006, 26(5): 1297-1302.]

[38 ] Nie LQ, Wu Q, Rao B et al. Leaf litter and soil carbon, nitrogen, and phosphorus stoichiometry of dominant plant species in the Poyang Lake wetland. Acta Ecologica Sinica, 2016, 36(7): 1898-1906. [聂兰琴, 吴琴, 尧波等. 鄱阳湖湿地优 势植物叶片-调落物-土壤碳氮磷化学计量特征. 生态学报, 2016, 36(7): 1898-1906.]

[39] Lee AA, Bukaveckas PA. Surface water nutrient concentrations and litter decomposition rates in wetlands impacted by agriculture and mining activities. Aquatic Botany, 2002, 74(4) : 273-285.

[40] Zheng YQ, Liu JS, Wang JD et al. Variation of chemical elements of Carex lasiocarpa litter in Sanjiang Plain. Grassland of China, 2000, (3) : 13-17. [郑玉琪, 刘景双, 王金达等. 三江平原典型沼泽生态系统毛果苔草枯落物中化学元素 变化分析. 中国草地, 2000, (3) : 13-17.]

[41] Gessner MO. Mass loss, fungal colonization and nutrient dynamics of Phragmites australis leaves during senescence and early aerial decay. Aquatic Botany, 2001, 69(2/3/4) : 325-339.

[42] Frouz J. Effects of soil macro- and mesofauna on litter decomposition and soil organic matter stabilization. Geoderma, 2018, 332: $161-172$.

[43] Wu Q, Yao B, Xing RX et al. Distribution pattern of soil organic carbon in Poyang Lake wetland and related affecting factors. Chinese Journal of Ecology, 2012, 31(2): 313-318. [ 吴琴, 尧波, 幸瑞新等. 鄱阳湖典型湿地土壤有机碳分布 及影响因子. 生态学杂志, 2012, 31(2): 313-318.]

[44] Yue K, Yang WQ, Peng Y et al. Effects of streams on lignin degradation during foliar litter decomposition in an alpine forest. Chinese Journal of Plant Ecology, 2016, 40(9) : 893-901. [岳楷, 杨万勤, 彭艳等. 高寒森林溪流对调落叶分解 过程中木质素降解的影响. 植物生态学报, 2016, 40(9): 893-901.]

[45] Ouyang LH. Litter decomposition and nutrient dynamics in the Minjiang River estuarine wetland[Dissertation]. Fuzhou: Fujian Normal University, 2014. [欧阳林梅. 闽江河口湿地枯落物分解与养分动态特征研究 [学位论文]. 福州: 福 建师范大学, 2014.]

[46] Peng Y, Yang W, Yue K et al. Impacts of soil fauna on nitrogen and phosphorus release during litter decomposition were differently controlled by plant species and ecosystem type. Journal of Forestry Research, 2019, 30(3) : 921-930. DOI: 10. 1007/s11676-018-0664-z.

[47] Sanghaw R, Iwai CB, Choosai C et al. Initial contents of residue quality parameters predict effects of larger soil fauna on decomposition of contrasting quality residues. Agriculture and Natural Resources, 2017, 51(5) : 338-346. 